\title{
Mapping the Mined-Out Area Saturated by Water with Transient Electromagnetic Method
}

\author{
Chuantao $\mathrm{Yu}^{1,2, \text { a }}$, Xinyue Liü, b , En-guo Li ${ }^{2, \mathrm{c}}$ \\ ${ }^{1}$ College of Mining Engineering, Taiyuan University of Technology, Taiyuan 030024, China \\ 2 Shanxi Institute of Geological Survey, Taiyuan 030006, China,

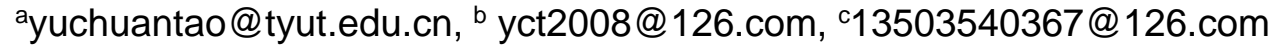

Keywords: Mined-Out Area; Transient electromagnetic method; Conductive; Resistivity.

Abstract: Mined-Out Area Saturated by Water is a serious threat to the safety coal-mining practices. This research focuses on detecting mined-out area saturated by water with transient electromagnetic method. Data acquisition system was arranged along 65 survey lines, and the total of 4830 survey points were recorded. An inversion technique was used to interpret the TEM data. The inversion results suggested that the mined-out areas saturated by water always exhibit a very low-resistivity, the Resistivity contour present closed circle sharp. And there are 8 mainly mined-out areas saturated by water, named JS9-1 to JS9-8 can be inferred by TEM, the interpretation result was verified by drilling, which prove the inferences of the TEM survey are excellent and that TEM is an efficient way to investigate mined-out area saturated by water.

\section{Introduction}

Transient electromagnetic method (TEM) is an important branch of geophysical methods, and has been widely used in various fields[1] such as engineering, mining, urban construction, tunnel prediction, and groundwater investigation[2]. Due to its sensitivity to conductive geologic body compared to the surrounding rocks with high resistivity, TEM has received great attention in hydro-geophysical investigations[3].

China is currently the world's largest coal miner, and it is also the largest consumer of coal in the world. The start of the $21^{\text {st }}$ century was a golden era for the coal sector, rapid expansion of coal firms led to huge profits. However, based on China's existing technologies, the mining coal lead to huge mined-out regions. In most coal fields in China, the mined-out regions are saturated by water, which poses a serious threat to coal-mining practices[4]. Therefore the detection of the mined-out areas, especially the water-filled mined area, is one of the most important issues[5].

In this paper, the TEM method has been used to investigate geological structures and electrical characteristics in order to map the water-enriched mined-out areas within the survey region.

\section{Geologic setting}

The survey region is located in the central part of Lingshi City, Shanxi Province, China. The survey region is typically a loess hilly area, the top of the mountain is extensively covered by loess and dense vegetation, (Fig. 1). The elevation of the survey area sharply changes at different sites. The highest point with an elevation of $1099 \mathrm{~m}$ is located at the top of the mountain in the northwest part, and the lowest point with an elevation of $869.2 \mathrm{~m}$ is located in the valley of the southeastern part of the survey area, (Fig. 2).

The strata from youngest to oldest in the survey area are Quaternary(Q), Upper Shihezi formation $\left(\mathrm{P}_{2} \mathrm{~s}\right)$, Lower Shihezi formation $\left(\mathrm{P}_{1} \mathrm{x}\right)$ and Shanxi formation $\left(\mathrm{P}_{1} \mathrm{~s}\right)$ of Permian, Taiyuan formation 
$\left(\mathrm{C}_{3} \mathrm{t}\right)$ and Benxi formation $\left(\mathrm{C}_{2} \mathrm{~b}\right)$ of Carboniferous and Fengfeng formation $\left(\mathrm{O}_{2} \mathrm{f}\right)$ of Ordovician, respectively. According to the borehole ZK001 and geophysical measurements, the stratum distribution, lithology, and electrical property of the survey area are listed in Table 1[6].

Table 1. Stratum parameters of the survey area.

\begin{tabular}{|c|c|c|c|}
\hline \multicolumn{2}{|l|}{ Stratum } & Lithology & Resistivity $\Omega \cdot \mathrm{m}$ \\
\hline \multicolumn{2}{|c|}{ Quaternary（Q） } & $\begin{array}{l}\text { Loess and } \\
\text { alluvium }\end{array}$ & $40-80$ \\
\hline \multirow{3}{*}{ Permian } & Upper Shihezi formation $\left(\mathrm{P}_{2} \mathrm{~s}\right)$ & \multirow{3}{*}{$\begin{array}{l}\text { Sandstone, sandy } \\
\text { mudstone, and coal }\end{array}$} & \multirow{3}{*}{$30 \sim 300$} \\
\hline & Lower Shihezi formation $\left(\mathrm{P}_{1} \mathrm{x}\right)$ & & \\
\hline & Shanxi formation $\left(\mathrm{P}_{1} \mathrm{~s}\right)$ & & \\
\hline \multirow[t]{2}{*}{ Carboniferous } & Taiyuan formation $\left(\mathrm{C}_{3} \mathrm{t}\right)$ & $\begin{array}{l}\text { Sandstone, } \\
\text { siltstone, } \\
\text { mudstone, } \\
\text { limestone, and coal }\end{array}$ & $240-300$ \\
\hline & Benxi formation $\left(\mathrm{C}_{2} \mathrm{~b}\right)$ & $\begin{array}{l}\text { Sandy mudstone, } \\
\text { bauxite, limestone }\end{array}$ & $220-320$ \\
\hline Ordovician & Fengfeng formation $\left(\mathrm{O}_{2} \mathrm{f}\right)$ & Limestone & (If water-free) \\
\hline
\end{tabular}

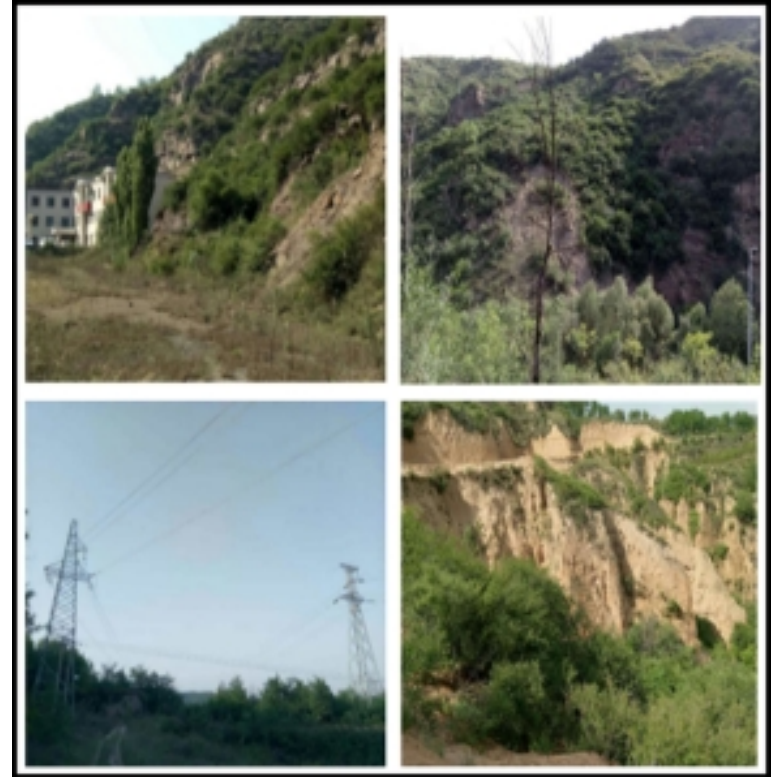

Fig. 1. Some photos of the survey area.

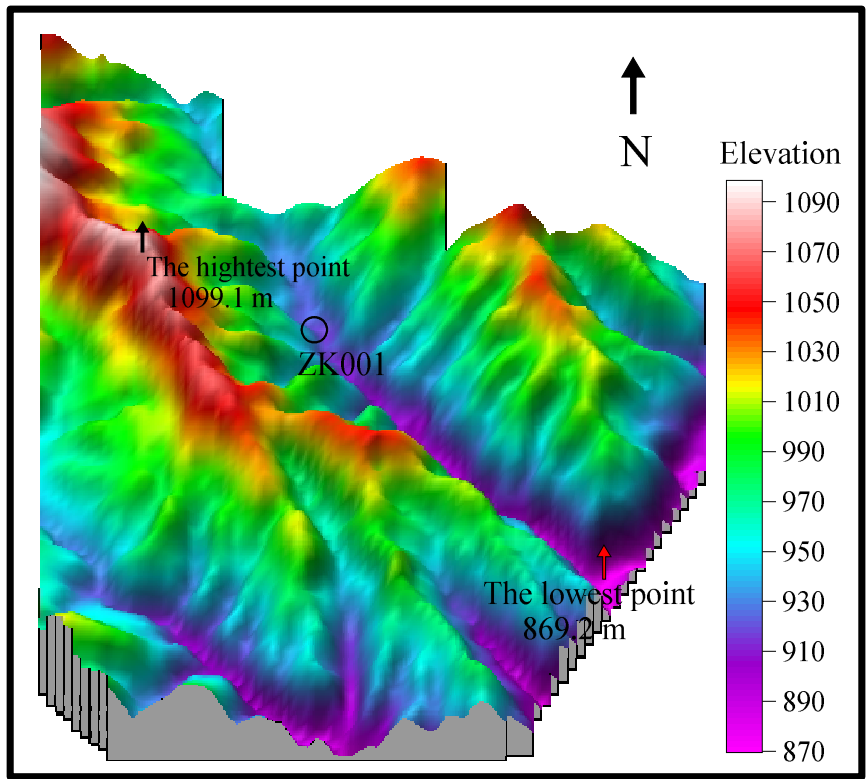

Fig. 2. Topographic map of the survey area

\section{Data acquisition}

Data acquisition system was arranged along 65 survey lines, the interval of the lines was $40 \mathrm{~m}$, and the survey sites along the survey line with the interval of $20 \mathrm{~m}$ covers an area of $3.8 \mathrm{~km}^{2}$, and the total of 4830 survey points were recorded. The GDP-32 system developed by Zonge Engineering and Research Organization was adopted in our measurements, and a magnetic sensor with effective receiving areas of $10000 \mathrm{~m}^{2}$ was used to receive the induced voltage. Note that the loop size is $480 \times 480 \mathrm{~m}$, the strength of the transmitting current is $8 \mathrm{~A}$, and the base frequency is 
$16 \mathrm{~Hz}$ for the loop TEM measurements.

\section{Data processing}

The TEM data analysis consisted of many components, as follows: data pro-processing, qualitative analysis, data inversion, and subsequent geological interpretation of the results. Before the inversion, preprocessing work must be done to the raw data. In view of the characteristics of the wide frequency band and fast attenuation of the TEM signal, it is difficult to directly smooth the decay curve of one measurement point. Therefore, we make the five-point smoothing to the data of the same time channel but of different measuring points. Then, we inverted the smooth data using the TEMINV procedures.

\section{Data interpretation}

Figs.3 and 4 show the inversion results for profiles number 880 and 2040. According to the results of the inversion, the resistivity tendency of the survey area is low-medium -high from shallow to deep. The cross-section diagram with blue color on behalf of geological structures with low-resistivity, and the red color represent high-resistivity. And the color blue-green-yellow-red indicated the resistivity is increased. In line 880, There are two main blue parts with the resistivity less than $30 \Omega \cdot \mathrm{m}$ were interpreted as mined-out areas saturated by water.

Fig. 5 gives the apparent resistivity plane contour map of the No.9 coal bed at the elevation from 730- $760 \mathrm{~m}$. The results shows that there are main eight part of blue areas exist in the survey area. That is to say, there are mainly 8 mined-out areas saturated by water, named JS9-1 to JS9-8. In order to verify the interpretation result, a borehole about $600 \mathrm{~m}$ depth was drilled in the center JS9-3. The drilling results agreed well with interpretation result.
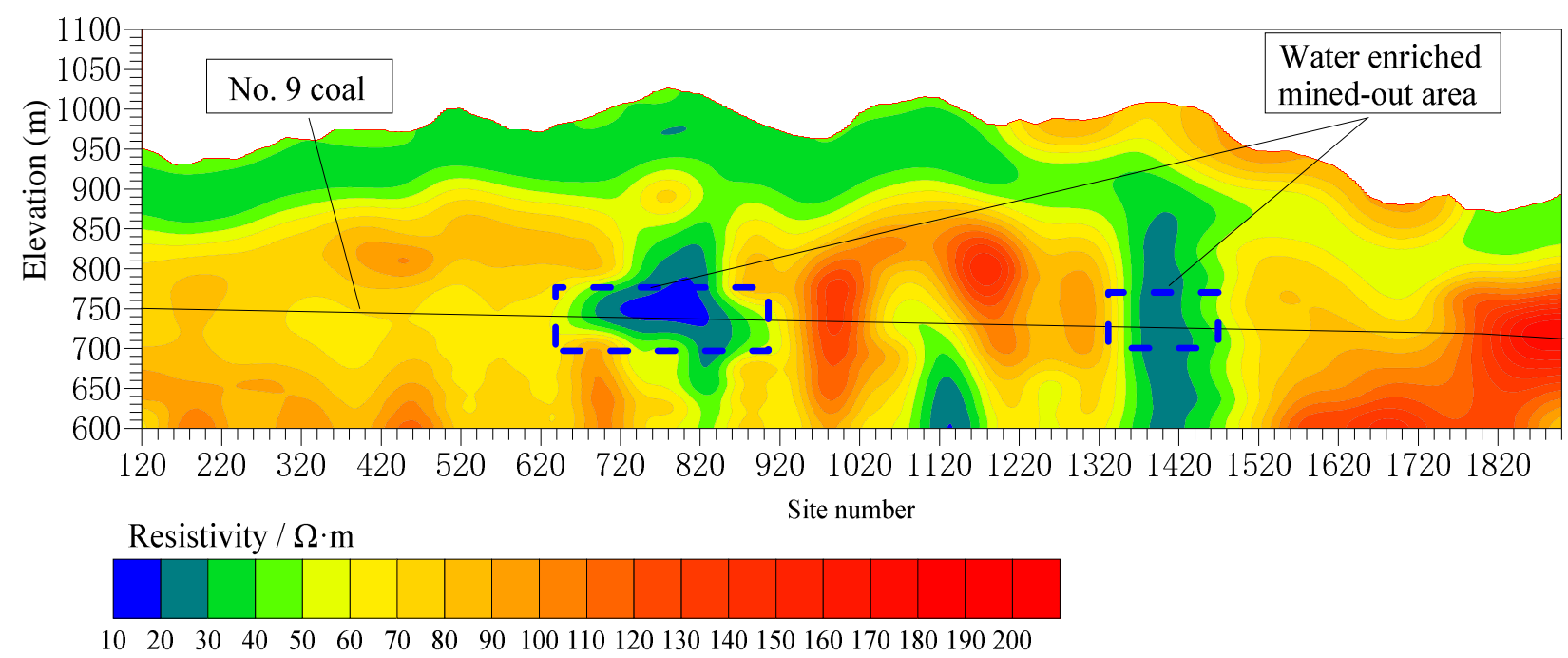

Fig. 3. Inversion results of line 880 


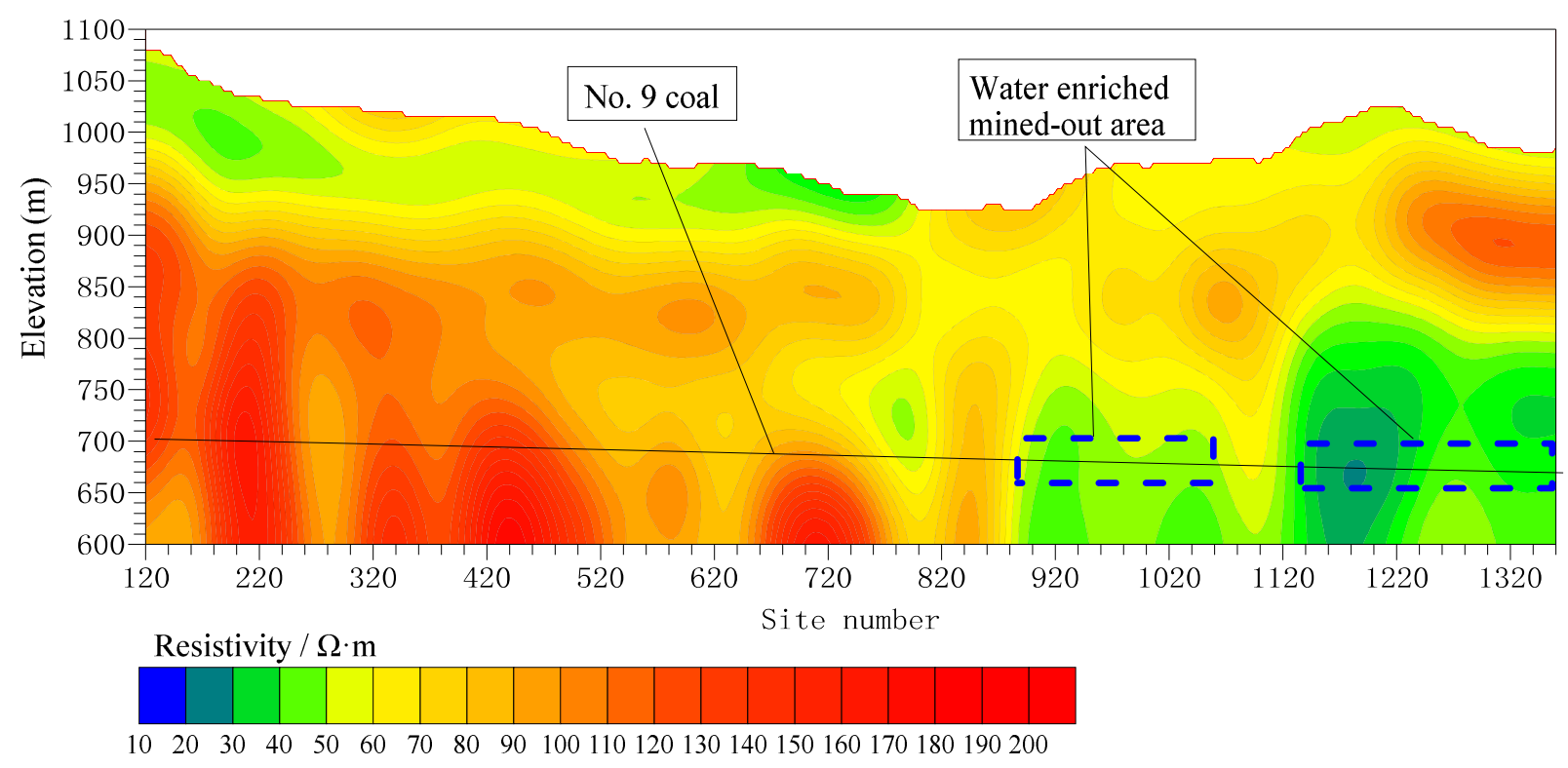

Figure.4. Inversion results of line 2040

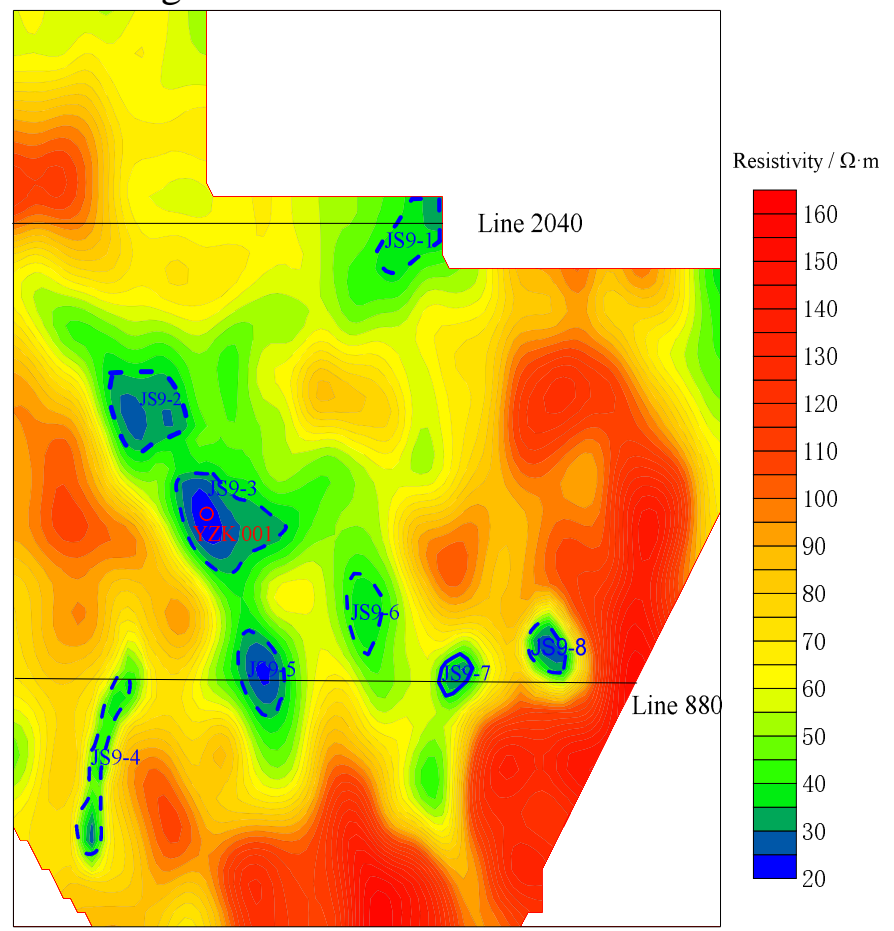

Fig.5. The apparent resistivity plane contour map of the No.9 coal bed

\section{Conclusion}

TEM was successfully used to map mined-out areas saturated by water investigation and the following conclusions were obtained: (1) the mined-out areas saturated by water always exhibit a very low-resistivity, the Resistivity contour present closed circle sharp. (2) There are 8 mainly mined-out areas saturated by water, named JS9-1 to JS9-8 can be inferred by TEM, the interpretation result was verified by drilling. (3) TEM is an efficient way to investigate mined-out area saturated by water.

\section{Acknowledgments}

We appreciate the financial support of the Basic research of Shanxi Province (Grant no. 
201601D202085).

\section{References}

[1] K. MacLennan, Y. Li: Signal extraction from 4D transient electromagnetic surveys using the equivalent source method: Geophysics, 76, no. 3, F147-F155 (2011).

[2] D. V. Fitterman, and M. T. Stewart: Transient electromagnetic soundings for groundwater: Geophysics, 51, 995-1005 (1986).

[3] G. Q. Xue, C. Y. Bai, S. Yan, S. Greenhalgh, M. F. Li, and N. N. Zhou: Deep sounding TEM investigation method based on a modified fixed central-loop system: Journal of Applied Geophysics, 76, 23-32 (2012)

[4] H. Li, G. Q. Xue, P. Zhao: The Hilbert-Huang transform based denoising method for the TEM response of a PRBS source signal. Pure and Applied Geophysics, 173, 2777-2789 (2016).

[5] B.Y. Su, J.C. Yu, C.X. Sheng, Y.L. Zhang: Maxwell-Equations Based on Mining Transient Electromagnetic Method for Coal Mine-Disaster Water Detection, ELEKTRONIKA IR ELEKTROTECHNIKA.Vol: 23 (3): 20-23 (2017)

[6] W.Y. Chen, G.Q. Xue, A.L. Olatayo, K. Chen, et al: A comparison of loop time-domain electromagnetic and short-offset transient electromagnetic methods for mapping water-enriched zones- A case history in Shaanxi, China.” GEOPHYSICS, 82(6), B201-B208 (2017). 